\title{
El feminismo filosófico en España: entrevista a Celia Amorós *
}

\author{
Philosophical Feminism in Spain: An Interview \\ with Celia Amorós \\ Luz Stella León HeRnÁndez y Celia Amorós Puente \\ UNED, Madrid
}

RESUMEN. A través de las preguntas sobre su trayectoria como filósofa feminista ilustrada, la relación entre la teoría y la práctica feministas, la situación del feminismo en la actualidad y sus metas y proyectos más urgentes, entre otras, Celia Amorós - máxima representante, junto a Amelia Valcárcel, de la teoría feminista filosófica de la igualdad - nos «ilustra» sobre los retos del feminismo como movimiento ilustrado, emancipador y radicalmente igualitarista. Al hilo de su narración van surgiendo temas fundamentales como la globalización, el multiculturalismo, las políticas de igualdad, la alianza de civilizaciones, la necesidad de buscar «vetas de Ilustración», entre otros. Temas urgentes que nos exigen confrontarlos, pasarlos por el tamiz del feminismo, con la certeza de que «las mujeres nos lo jugamos todo» como internacionalismo porque, como se nos dice aquí, o la liberación de las mujeres se da en todas partes o no se da, pues siempre puede haber involuciones.

Palabras clave: Celia Amorós, feminismo e ilustración, emancipación de las mujeres.

* Por motivos completamente ajenos a su voluntad, Celia Amorós no ha podido colaborar con este número, tal como estaba previsto desde un principio. Además de ser pionera en los estudios feministas de nuestro país, Celia Amorós fue también quien editó el número monográfico que la revista Isegoría, muy poco tiempo después de aparecer, dedicó al tema de Feminismo y ética allá
Abstract. Celia Amorós is the major contributing feminist philosopher of the Enlightenment in Spain. Not only because of her research about the correlation of theoretical and practical feminism, but also because of her mapping of actual feminism, its main aims and projects. Together with Amelia Valcárcel, Amorós is also one of the main feminists of equality, since she traces the goals of feminism as an enlightened, freeing and radical movement. Along this interview, main contemporary key issues -as globalization, multiculturalism, equality policy or the alliance of the civilizations - are explored from her feminist contribution. It is becoming increasingly difficult to ignore the contributions of feminism to these subjects. In addition, the working out of local feminisms plays a key role in global women's emancipation in an attempt of avoiding the suffering from several major drawbacks.

Key words: Celia Amorós, Feminism and Enlightenment, Woman's Emancipation.

por 1992 en su número 6 (http://isegoria.revistas.csic.es/ index.php/isegoria/issue/view/20). Esta entrevista, realizada por una de sus colaboradoras, intenta paliar su ausencia y rendir un homenaje a quién es referente insoslayable en el feminismo de habla hispana, y por ello nos hemos decidido, con carácter excepcional, a integrarla en este número, pese a no estar inédita, dado que su inclu- 
LUZ STELLA LEÓN HERNÁNDEZ (S. LEÓN) ¿En qué momento de su trayectoria profesional como filósofa se declara feminista?

Celia Amorós Puente (C. Amorós) Mi sensibilización se produjo básicamente en solitario, al hilo de las experiencias personales y de algunas lecturas que fueron fundamentales para mí en esos años, por ejemplo, Simone de Beauvoir, que estaba en la línea de mis posiciones existencialistas; o La mística de la feminidad de Betty Friedan, que presenté cuando era representante estudiantil en Valencia. Ya en aquel entonces me preocupaba contextualizar las luchas por la emancipación de las mujeres en el marco de la lucha antifranquista y anticapitalista.

Otro libro importante fue Psicoanálisis y Feminismo, de Juliet Mitchell. Sin duda hoy mantendría posiciones más críticas con su teoría, pero en su día me sirvió para contrastar los rendimientos que podrían dar el estructuralismo - corriente por la cual estaba interesada, pues hice mi tesis sobre Mitológicas de Lévi-Strauss-. Me quedó abierto, de este modo, un amplio campo que fue dando forma teórica a mis preocupaciones militantes y que se plasmó en diferentes trabajos y, por fin, en mi libro Hacia una crítica de la razón patriarcal. En aquel entonces me preocupaba muy especialmente el feminismo como ética, sin minimizar el feminismo como movimiento social.

Por otro parte, tomé partido en la polémica del llamado «feminismo de la diferencia» $\mathrm{y}$ «feminismo de la igualdad», posicionándome en este último, pero haciéndole más concesiones al feminismo de la diferencia del que luego le haré al constatar los indeseables efectos políticos que produce.

Por otro lado, fue importante mi amistad con Amelia Valcárcel con quien entablé una comunicación intelectual y que ha sido para mí un referente. También mi contacto con Alicia Puleo, una mujer sumamente valiosa e inteligente. De esos mismos años conservo entrañable amistad con Luisa Posada, Ana de Miguel, Rosa Cobo, Cristina Molina, Amalia González e Inmaculada Cubero, etc., a las cuales considero un poco como hijas...

Entre mis primeros trabajos como feminista se encuentra el que editó Ángeles Durán, Sesgos patriarcales en el discurso filosófico. Presenté en la Universidad de La Laguna, donde había sido invitada junto con Javier Muguerza, Ludolfo Paramio y Tomás Pollán, un trabajo sobre ética feminista que representó para mi, digamos en la terminología taurina, la toma de la alternativa, el respaldo de los filósofos del establisment de izquierda para mi quehacer filosófico feminista.

S. LEÓN: Como filósofa feminista ilustrada, podemos decir jueza y parte en la construcción del feminismo de la igualdad, ¿cuál es la imagen más representativa de esos orígenes?

C. AMORÓS: Yo la relacionaría con los comienzos del Seminario «Feminismo e Ilustración» que comenzó en el curso $87 / 88$, al que acudieron investigadoras como Alicia Puleo, Ana de Miguel, Rosa Cobo, Concha Roldán, Luisa Posada, e invitadas como Cristina Molina, digamos que las considero como el grupo fundacional. También es importante recordar mi colaboración con el grupo de las his- sión en este nuevo monográfico permitirá encontrarla con más facilidad, no sólo en la versión impresa, sino también a través de Internet. Una versión electrónica de este documento fue publicada, junto con otra entrevista a
Amelia Valcárcel, en la revista Labrys, études féministes. www.unb.br/ih/his/gefem/labrys10/sumarioes panha.htm $\mathrm{y}$ en www.giocondaespina.com.ve/ GIOCONDA/PDFs/ la-teoria-critica-feminista-LuzEstella.pdf 
toriadoras, el grupo fundacional del Instituto de Investigaciones Feministas de la Universidad Complutense, donde destacaba la figura entrañable de Carmen García Nieto fallecida hace unos años. Pues bien, se puso de largo ese Instituto en el año 1989 con la celebración del bicentenario de la Revolución Francesa. Empapelamos toda la Complutense con un cartel que aún conservo. Lo que hicimos fue reconstruir, con fuentes francesas sobre todo, lo que significaba la Revolución Francesa para las mujeres.

En el 89 también se puso en marcha el curso de Historia de la Teoría Feminista que tuvo lugar en el Salón del Instituto de la Mujer de la calle Almagro de Madrid y por el que han pasado muchas feministas. Creo que ha sido un elemento que ha contribuido a la conciencia histórica del movimiento feminista español y su proyección latinoamericana...

Para reconstruir mi relación con Latinoamérica, he de decir que para mi fue muy importante la invitación de Haydée Birgin, Presidenta de la Comisión de Familia del Senado en aquel entonces, a dar un ciclo de conferencias en Buenos Aires. Allí se urdió un vínculo entrañable, que dura hasta nuestros días, con investigadoras feministas que son a la vez amigas personales, como María Luisa Femenías. Y podría citar muchas otras...

Por otra parte, introduje la temática de la teoría y crítica feministas en algunos cursos de doctorado que di por aquellos años, como «Mujer, no ser y mal», así como sobre las polémicas en torno a las figuras posmodernas de deconstrucción del sujeto y la lucha por reconstruir lo que podría ser un sujeto feminista.

Otro hito importante fue mi estancia en Harvard en el 93 porque me interesaban entonces las posiciones de Seyla Benhabib.

Y por último estoy muy orgullosa de algo que costó mucho esfuerzo, pero que por fin conseguí y fue introducir en la Universidad Complutense como asignatura optativa la «Teoría y Crítica Feminista», materia que hoy cuenta cada vez con mas alumnos y está asentada.

S. LEÓN: ¿Cuál es la relación entre teoría y práctica? y ¿cuál es la función de la teoría feminista?

C. AMORÓS: La función de la teoría feminista como toda teoría, ya lo dice su raíz griega, es «hacer ver». Pero la teoría feminista tiene la particularidad, como lo he dicho en muchas ocasiones, de que su hacer ver es inseparable de un irracionalizar, las relaciones jerárquicas entre los sexos en multitud de ámbitos. Eso sólo se deja ver a la mirada crítica: la mirada convencional ni siquiera lo discierne. Y por ello la teoría feminista va íntimamente unida al feminismo como movimiento social, pues, tal como lo señalan teóricos de los movimientos sociales como Melucci y Ana de Miguel, los Movimientos Sociales son «laboratorios culturales» que operan transformando la sensibilidad social ante determinados fenómenos: así, podemos llamar ahora actos de «violencia de género» a lo que antes se denominaba «crimen pasional». Se trata de una verdadera transformación epistemológica y política a la vez, porque, insisto en ello una vez más, conceptualizar es politizar.

S. LEÓN: En tantas «sendas de Ilustración» transitadas, la conquista de la individualidad es una tarea colectiva en la que vosotras habéis colaborado de forma decisiva. Ahora bien, ¿en qué situación estamos? ¿Cuáles siguen siendo los puntos vulnerables del proyecto emancipatorio y universalista feminista?

C. AMORós: Yo no creo que tengamos puntos vulnerables. Lo que si tenemos son puntos enormemente difíciles de llevar a la práctica porque las resistencias a que las mujeres sean individuos es de una tenacidad que todavía nos sorprende: los 
comunitarismos, los multiculturalismos, los regímenes teocráticos e incluso nuestras actuales democracias presentan en este punto el hueso más duro de roer. $\mathrm{Si}$ las mujeres son individuos, los aspectos más indeseables de la organicidad social no se pueden mantener. En una sociedad en que las mujeres tuvieran reconocido un estatuto de individualidad plena, la capacidad crítica y reflexiva de esa sociedad se incrementaría de un modo sorprendente, y la cohesión social podría ser reconstruida sobre bases nuevas de lucidez, capacidad reflexiva, autocrítica, y redefinición del contrato social.

S. LEÓN: ¿Cómo concibes la individualidad?

C. AMORÓS: Bueno, Duns Scoto, en el siglo XIV, definía el principio de individuación como la ultima solitudo, aquel reducto del sujeto que no se deja absorber por los predicados, sobre todo si esos predicados son producto de la heterodesignación. Es el reducto de la libertad y de la dignidad, y habría que redefinir la dignidad como ultima solitudo para desmarcarla de la definición tradicional de la dignidad, de las mujeres como una cualidad adjetiva, dependiente de su función de ser las depositarias del honor del varón.

S. LEÓN: Como feminista, filósofa y catedrática ¿qué avances significativos puede resaltar en el ámbito académico y cultural después de tantos años de arduo y constante trabajo no siempre reconocido?

C. AMORós: Bueno, pues que cada vez en mayor medida es aceptada con normalidad en los medios y en el discurso académico la temática del feminismo. Tan es así que los propios varones se interesan cada vez más por ella y, en esa medida, las prestigian, porque, nos guste o no, son los varones los que prestigian en última instancia lo que tocan. Pero, afortunadamente cada vez tienen que compartir más con nosotras los criterios acerca de lo que es de recibo y lo que no lo es en el ámbito académico.

S. LEÓN: ¿Hay recambio generacional en el feminismo español? ¿Cuál es la deriva del mismo en comparación con el resto de los feminismos mundiales?

C. AMORÓS: Definitivamente sí hay un recambio generacional en las temáticas que les interesan a estas nuevas mujeres. $\mathrm{Su}$ vivencia en la discontinuidad de lo que a ellas les preocupa y lo que ha sido la tradición feminista está muy en la línea de la sensibilidad de nuestra era de la globalización, en que todo ocurre en tiempo real. Se pierde así la idea de continuidad, de profundidad histórica de cualquier tipo de fenómeno. Esto es un verdadero problema porque el conocimiento de lo que ha sido la teoría y la lucha de las mujeres durante siglos, y que hace posible que, aun con discriminaciones, las mujeres tengan acceso a las nuevas tecnologías, a las redes, a las posibilidades de relacionarse a escala mundial verdaderamente insólitas, es un instrumento muy importante para el empoderamiento de las mujeres. Incluso para darle un sentido a su lucha para que no se reproduzcan las relaciones patriarcales de poder en el mundo virtual de las nuevas tecnologías. La tradición feminista tiene todavía una capacidad para modelar concepciones y sensibilidades que son necesarias para esta lucha... Por contestar a tu segunda pregunta, no creo que el feminismo español sea en ésto particularmente diferente... A mi misma me cuesta percibirlo, no se qué es producto específico de ese feminismo español... Concretamente, nuestro producto, pequeño por supuesto, ha sido el trabajo de muchos años. Ahora bien, ¿con qué otros elementos ha podido converger? No lo se; me resulta difícil saber en qué medida como investigadoras hemos tenido que ver con otros desarrollos. Hemos trabajado muchísimo para elevar el nivel teórico del feminismo es- 
pañol, hemos hecho en ese sentido un gran esfuerzo, pero en eso somos juez y parte: no tenemos la perspectiva para calibrarlo. No puedo decirte si se puede percibir la influencia del feminismo español: el feminismo latinoamericano ha tenido unos desarrollos, unas respuestas determinadas ante los procesos de globalización y la feminización de la pobreza: todo esto en España no ha tenido las mismas repercusiones. El impacto de la globalización se ha sufrido mucho más en Latinoamérica, por ello yo insisto en que debemos pensar que la globalización es un reto fundamental, y entender el sentido de las nuevas misoginias de la era global, como la que ha llevado a los crímenes de Ciudad Juárez. La misoginia a nivel global tiene unas especificidades y creo que hay que ver cuáles son para luchar contra ellas porque están produciendo verdaderos espantos. Hace falta volver a estudiar el fenómeno de la misoginia.

Yo diría que la misoginia no es un explanans sino un explanandum, es decir, algo que a su vez debe ser explicado. El fenómeno de la misoginia como odio a las mujeres y el querer destruirlas hay que estudiarlo especialmente en la era global.

S. LEÓN: ¿Cuál es el balance de los últimos años de feminismo español?

C. AMORÓS: Yo creo que es un balance muy positivo: se ha conseguido una ley de igualdad, unos niveles de «des-asnamiento» respecto a las cuestiones de las mujeres que es ampliamente significativo. Se han cometido errores: desde luego, los movimientos feministas debieron haber participado más. Pero sigue habiendo una gran asignatura pendiente, un hueso duro y es el cuarto supuesto de la ley del aborto, con el que no se atreven los políticos y donde hacen unas concesiones que no son admisibles... Pero, si nos comparamos con los países del entorno no sali- mos mal paradas teniendo en cuenta que nuestro punto de partida fue el franquismo. Si nos hubieran dicho en los años de la transición que treinta años más tarde habría un gobierno paritario no lo hubiéramos podido creer. En cuanto a las leyes, están insuficientemente dotadas, hay que seguir poniendo el dedo en la llaga, hay que hacer ver, por ejemplo, la gravedad de la custodia compartida en el caso de los maltratadores porque no podemos tener un policía para controlar cada fin de semana las idas y venidas de esos maridos...

S. LEÓN: Como vosotras nos habéis enseñado el feminismo implica transformación en las relaciones de poder: ¿se percibe un cambio real y/o simbólico en el ejercicio del poder de las mujeres?

C. AMORÓs: Vamos a ver, si pensamos en mujeres como Hilary Clinton, Condoleezza Rice, Ségolène Royal o Angela Merkel parece que empieza a haber un cambio apreciable en las posiciones de poder de las mujeres. El poder, en esa medida, se presenta como siendo de cualquier sexo, como una normalización, en la escala misma de la especie, de lo que era un acaparamiento por el sexo masculino que resultaba hasta procaz.

S. LEÓN: Hoy en España tenemos un gobierno paritario y política de igualdad de género: ¿Con qué argumentos «fuertes» contamos para legitimar ese poder emergente de las mujeres? ¿Contamos con una infraestructura institucional, teórica y política para mantenernos y avanzar en esas posiciones alcanzadas?

C. AMORÓS: Tenemos argumentos a priori tan fuertes como los basados en el valor de la igualdad, cuya fortaleza ha resultado de una lucha de siglos sin que se diera nunca por descontado; y, por otro lado, todo lo que venimos aportando a lo largo de la historia y que empieza a emerger en múltiples investigaciones. Ante todo, hay que tener una idea clara de lo que es la 
igualdad y lo que significa, y no confundirla con la identidad, ni con la uniformidad. Hacer de ella, como lo decía Poullain de la Barre, no solamente una idea, sino un sentimiento moral, una idea-fuerza con capacidad clarificadora y transformadora; a la luz de este concepto es como podemos percibir los fenómenos de desigualdad en todos los niveles de la sociedad en que se producen y se reproducen, genera una sensibilidad social en la que cualquier manifestación de desigualdad resulte chirriante e intolerable: se generará así una demanda social capaz de presionar, como ya está ocurriendo, para que los y las políticas articulen políticas de igualdad desde el instrumento de la Ley y lograr así una sinergia entre las intervenciones políticas y la labor social: ninguna de ellas puede realmente ser eficaz si se descuida la otra. Para decirlo kantianamente, leyes políticas de igualdad sin la sensibilidad social correspondiente serán vacías, una sensibilidad social que no se plasme en intervenciones políticas corre el riesgo de ser ciega.

S. LEÓN: ¿Seguimos teniendo problemas con la solidaridad, con el «nosotras»?

C. AMORÓs: Seguimos teniendo problemas, porque no cabe duda que problemas como la globalización del cuidado, por ejemplo, el tener a las mujeres del tercer mundo como cuidadoras del primer mundo... esto pone a prueba nuestra solidaridad. Las mujeres del primer mundo no podemos olvidar que los éxitos conseguidos por nosotras tras muchos años de luchas ahora peligran por ello es más necesaria que nunca promover el internacionalismo feminista, la emancipación de las mujeres lo será de todas o no será.

Las mujeres tenemos algo común por encima de las diferencias: ellos saben siempre que han de pactar y cómo pactar, nosotras deberíamos educarnos en la cultura del pacto y ejercitarlo.
S. LEÓN: ¿Cuáles son las perspectivas actuales y de futuro del discurso feminista?

C. AMORÓs: Creo que el discurso feminista en la actualidad tiene un cometido muy importante es el de clarificar qué sea la democracia: tiene que disponer de toda una batería de preguntas para pasar un test de democracia a todo tipo de regímenes. El feminismo y la democracia nacieron de un mismo parto y ahora que la democracia se encuentre en una situación tan difícil en algunos ámbitos por la intransigencia y en otros por la indiferencia, la posición de las mujeres es el test definitivo de la democracia.

S. LEÓN: ¿Cuáles son los retos para el feminismo ilustrado como movimiento social, si tenemos en cuenta la globalización y la realidad cambiante?

C. AMORÓS: El feminismo ilustrado, para poder dar respuesta a los problemas que se nos plantean a nivel global, debe tener una gran sensibilidad para la complejidad del mundo globalizado en el que estamos.

El proyecto ilustrado tiene que contrastar su pretensión de universalidad en un mundo que se nos da, por fin, como uno, como un solo mundo universal y global: tiene que despojarse de ese modo de todos los sesgos ilegítimos que se han derivado de la adopción de lo que Seyla Benhabib llama «universalidades sustitutorias» y que implica la crítica radical del androcentrismo, el etnocentrismo, del eurocentrismo y, como lo afirma Sophie Bessis, de la cultura de la supremacía de Occidente. Habrá de atender a las aportaciones de todas las culturas a un «universalismo interactivo», pero la lucha, precisamente porque occidente hace un uso despótico y a su medida de ciertos postulados de la Ilustración, la tarea va a contrapelo de curso del mundo. Hemos de ser muy lúcidas y muy tenaces porque a las mujeres nos va todo en que el proyecto ilustrado pueda desarrollarse a escala universal y desde una perspectiva de uni- 
versalidad... por eso digo que hay que adoptar un trotskismo feminista: el feminismo en una sola región del mundo puede acabar siendo feminismo en ningún lugar del mundo.

Se ha dicho que en las alianzas de los feminismos con los movimientos antiglobalización éstos habrían aprendido viejas formas de actuación feminista. Pero, por otra parte, parecen encontrarse actualmente en un cierto impasse. Sería por ello importante seguir manteniendo alianzas en orden a conservar y fortalecer el Estado de Bienestar para las mujeres. No debemos perder de vista que la lucha contra la precarización laboral nos puede hacer retroceder al punto cero... y no digamos las luchas fronterizas, donde se explota el trabajo de las mujeres en las maquilas y donde el deterioro de el tejido social las expone como las presas más codiciadas de las bandas mafiosas.

S. LEÓN: ¿En qué medida puede el feminismo español tender puentes desde Occidente para, como afirmas, «civilizar» el conflicto de civilizaciones?

C. AMORÓS: Eso de «civilizar el conflicto de civilizaciones» es una expresión que he acuñado en polémica con el título del libro de Huntington El Conflicto de las civilizaciones... a nosotras nos ha tocado un lugar que no hemos elegido: es privilegiado, por suerte o por desgracia, podemos conocer el fenómeno de primera mano, y necesitamos tener criterios feministas sobre el tema de la inmigración. Está todo el mundo irritado, desconcertado, indignado, pero es aquí donde las feministas nos encontramos en una posición endiablada a la vez que privilegiada para habilitar fórmulas de asunción del proceso. Se habla mucho de los problemas de inserción laboral de los varones, y mucho menos de los de las mujeres, desde la globalización del cuidado hasta el tráfico de mujeres para la prostitución.

El multiculturalismo es un gran reto para el feminismo y para nuestra cultura de la igualdad. Para las mujeres especialmente, porque quienes lo mantienen se oponen a socializar a las mujeres en la conciencia y el uso de sus derechos humanos con el argumento de que se les imponen de ese modo esquemas ajenos a sus esquemas culturales.

Por otra parte, en el diálogo de las feministas occidentales y los llamados feminismos islámicos no habría que confundir la tolerancia con la ingenuidad... Tendríamos que centrarnos en qué contribuye y qué no contribuye a la emancipación de las mujeres, apoyándonos críticamente en los criterios que ha decantado nuestra historia y la filosofía, y ello nos pondrá en una posición de mayor legitimidad para hacer la crítica a planteamientos como el de Huntington. 